\title{
Influence of smart metering systems on increasing the accuracy of calculation electrical power losses in electrical networks
}

\author{
Timur Musaev 1,*, Marat Khabibullin ${ }^{1}$, Ramil Kamaliev ${ }^{1}$, Oleg Fedorov ${ }^{2}$, Ilgiz Valeev ${ }^{3}$, and Oleg Vladimirov ${ }^{3}$ \\ ${ }^{1}$ OAO Grid Company, 420094 Russia, Kazan, Bondarenko str., 3 \\ ${ }^{2}$ Nizhny Novgorod State Technical University n.a. R.E. Alekseev,603950 Russia, Nizhny Novgorod, Minin str., 24 \\ ${ }^{3}$ Kazan State Power Engineering University, 420066 Russia, Kazan, Krasnoselskaya str., 51
}

\begin{abstract}
The article discusses the possibility of using data from smart electricity meters (SEM) to increase the accuracy of calculation losses in $0.4 \mathrm{kV}$ low-voltage networks. An increase in accuracy can be achieved using actual data about the load graph of electricity consumers (in this case, 6(10)-0.4 kV transformer substations are meant). To date, the operating load factor is taken equal to 0.5 , which does not always correspond to the actual data. Using SEM, actual load graphs can be obtained, which enable more accurate determination of the operating load factor. Consequently, the accuracy of calculation of electrical energy losses will be increased.
\end{abstract}

\section{Introduction}

The modern electrical power industry is transformed under the influence of advances in technology. The Smart Grid (SG) technology is the most widely developed now. This term means the concept of a fully integrated, self-regulating and self-healing electrical power system with a network topology which includes all generating sources, main and distribution networks and all types of electricity consumers controlled by a single network of information-control devices and systems in real time [1-6].

Smart electricity meters (SEM) are one of the key technological areas and an important component of the modern energy system based on the SG concept [1]. SEM performs the following functions:

- Assessing the state of equipment and the level of network integration, showing the degree of information concentration in a single center;

- Providing continuous data monitoring and minimizing errors in invoicing arrangements;

- Contributing to the optimization of network modes and reduction of pollutant emissions by providing the consumer the ability to regulate the demand;

- Supporting more complex measurements and providing continuous data monitoring;

- Facilitating direct interaction between the service provider and the consumer.

Analysis of SEM functions shows that the issues of influence of metering systems on the process of calculating the amount of electricity losses in a network are not considered yet.

It should be noted that the loss or technological consumption of electrical energy during its transmission is the most important indicator of the efficiency of electrical network, and a clear indicator of the state of electricity metering systems [7,8]. At the same time, electricity is the only type of product transmitting of which doesn't require other resources, but a part of the transmitted energy itself is consumed [9]. Therefore its technological consumption is inevitable and the task is to determine its economically justified level. An important area of activity of any electrical power system enterprise (EPSE) is the organization of work on calculating the amount of losses in the electrical network, which is on the balance sheet of the enterprise.

Thus, the relevance of the study is in assessing the impact of the development of digital energy in general, and SEM in particular, on the correctness of formation of the estimated value of electricity losses.

The novelty of the research is in the application of big data, namely information on half-hour power received from the SEM, to improve the accuracy of calculations of electricity losses.

Today the calculation of electricity losses in a $0.4 \mathrm{kV}$ low-voltage network can be carried out using the method of assessing losses based on generalized information about the parameters of the network load schemes [10]:

$$
\Delta W=k_{0.4} \cdot\left(\frac{W_{0.4}}{N}\right)^{2} \cdot \frac{\left(1-d_{n}\right)^{2} \cdot\left(1+\operatorname{tg}^{2} \varphi\right) \cdot L_{E Q}}{F_{A V} \cdot D} \cdot \frac{1+2 \cdot k_{f}}{3 \cdot k_{f}}(1)
$$

where $k_{0.4}$ is the coefficient taking into account the load distribution along the length of the line;

$W_{0.4}$ is the electricity supply for the period, $\mathrm{kWh}$;

$N$ is the amount of electricity transmission lines, pcs;

* Corresponding author: musaevkgeu@ ramler.ru 
$d_{n}$ is the share of electricity consumed at a distance of 1-2 spans from the transformer substation, with respect to the total supply to the $0.4 \mathrm{kV}$ network, p.u.;

$F_{A V}$ is the average cross-section of the head sectors;

$L_{E Q}$ is the equivalent total length of lines, $\mathrm{km}$;

$k_{f}$ is the operating load factor, p.u.

Here the operating load factor is used, which determines the ratio of the average power to the maximum power for the considered period:

$$
k_{f}=\frac{P_{A V}}{P_{M A X}}
$$

$P_{A V}$ is the average power for the considered period.

$P_{M A X}$ is the maximum power for the considered period.

According to paragraph 2 [10], in the absence of data on operating load factor, it is assumed to be 0.5 . However, taking into account the technical level of development of modern EPSE and SEM, from which "big data" on power can be obtained, the coefficient can be calculated and the obtained value may differ significantly from that adopted according to [10]. This, in turn, leads to a change in the design value of electricity losses in the $0.4 \mathrm{kV}$ network.

Thus, the purpose of the study is to analyze the influence of "big data" received from SEM on improving the accuracy of calculations of technological consumption of electrical energy in $0.4 \mathrm{kV}$ low-voltage networks.

\section{Materials and methods}

In order to analyze the current state of issues on increasing the accuracy of calculations of electrical energy losses, a literary review of scientific and practical works in this area was carried out.

One of the ways to improve the accuracy of on-line calculations of electricity losses is the joint evaluation of losses in the 6(10)-0.4 $\mathrm{kV}$ distribution networks [11]. The informational supportability of the $6(10) \mathrm{kV}$ networks allows obtaining flow distribution in the line diagram by distribution of electricity recorded by metering devices at the head section of line. The information security of low-voltage networks is worse than that of the $6(10) \mathrm{kV}$ networks. Until recently, the problem of mode information in the $0.38 \mathrm{kV}$ power system did not find a solution due to the absence of measuring devices in transformer substations (TS), lack of funds for their installation and human resources to carry out the necessary measurements.

At the same time, all methods for losses evaluation can be conditionally classified into deterministic, probabilistic-statistical, probabilistic-deterministic [12]. The choice of methodology for calculating electricity losses is determined by many factors: the availability of initial data and the degree of complexity of their preparation, the availability of a computer and appropriate application software, and the readiness and interest of personnel in using modern methods for calculating electricity losses.

Another way to improve the accuracy of such calculations is to study the errors of the calculated electricity losses and power using regression relationships [13]. When using the method of on-line calculations of technical losses of electricity, negative methodological errors arise that underestimate the real losses [14]. Methodological errors are explained by the difference between the average current on the interval $T$ and the real current on the interval $t_{1}$ and $t_{2}$.

The operating load factors $k_{f}$ have a significant impact on the accuracy of calculations. The reference method for determining the coefficient uses the actual thirty-minute graphs of electrical load via the formula:

$$
k_{f}^{2}=\left(1+\frac{\Delta P_{C H}}{\Delta P_{M}}\right)
$$

Here $\Delta P_{M}$ is the main component of average electricity losses, which is the amount of power losses in the network, calculated at the average load in the network.

$\Delta P_{C H}$ is the changing component of losses:

$\Delta P_{C H}=\Delta P_{D}+\Delta P_{C O R}$

$\Delta P_{D}$ is the component, taking into account the dispersion of the load graph shape,

$\Delta P_{C O R}$ is the component that takes into account the mutual correlation of graphs.

In [15], it is concluded that in order to determine the operating load factor using the method described above, it is necessary to have information on the load graph, which in most cases excludes its application in practice. However, the development of SEM makes it possible to solve this problem.

The carried out literary analysis allows us to conclude that one of the ways to improve the accuracy of calculating electricity losses is to increase the reliability of information on operating load factor.

\section{Results. Theoretical study}

Increasing the reliability of information on operating load factor can be achieved by using big data obtained from intelligent electricity metering systems, in particular, half-hour power for the considered period. To obtain the adjusted coefficient, the following conditions must be met:

1. The calculation of electricity losses is carried out monthly, therefore, it is necessary to consider the integrity of half-hour power values for a month;

2. Taking into account the installation of SEM at the input of TS, the information should be collected from substations that are part of the region of electrical networks (REN), since the calculation of electricity losses is carried out separately for each REN;

Thus, the information required to calculate the operating load factor can be presented in the form of table 1. 
Table 1. Half-hour power for calculating the operating load factor.

\begin{tabular}{|l|c|c|c|c|c|}
\hline \multicolumn{1}{|c|}{ Hours } & TS No. 1 & TS No. 2 & TS No. 3 & TS No. 4 & TS No.... \\
\hline $00: 00$ & $P_{00: 00}^{1}$ & $P_{00: 00}^{2}$ & $P_{00: 00}^{3}$ & $P_{00: 00}^{4}$ & $P_{00: 00}^{n}$ \\
\hline $00: 30$ & $P_{00: 30}^{1}$ & $P_{00: 30}^{2}$ & $P_{00: 30}^{3}$ & $P_{00: 30}^{4}$ & $P_{00: 30}^{n}$ \\
\hline $01: 00$ & $P_{01: 00}^{1}$ & $P_{01: 00}^{2}$ & $P_{01: 00}^{3}$ & $P_{01: 00}^{4}$ & $P_{01: 00}^{n}$ \\
\hline$\ldots$ & $P_{h h: m m}^{1}$ & $P_{h h: m m}^{2}$ & $P_{h h: m m}^{3}$ & $P_{h h: m m}^{4}$ & $P_{h h: m m}^{n}$ \\
\hline $23: 30$ & $P_{23: 30}^{1}$ & $P_{23: 30}^{2}$ & $P_{23: 30}^{3}$ & $P_{23: 30}^{4}$ & $P_{23: 30}^{n}$ \\
\hline
\end{tabular}

Knowing the power for the period under consideration (for example, the calculated month), it is possible to select the average value for the set of substations under consideration. However when calculating the maximum power, certain questions arise. According to (1), the maximum power should be found from Table 1 (i.e. from the set of TS), which will lead to an unreasonable underestimation of the operating load factor. However, given the availability of information for each TS, the authors propose an approach to determine the maximum power for each substation and further averaging this value:

$$
\begin{gathered}
P_{M A X, i}=\max \left\{P_{i}\right\} \\
P_{M A X}^{A V}=\frac{\sum_{i=1}^{n} P_{M A X, i}}{n}
\end{gathered}
$$

$n$ is the number of transformer substations for which data are available.

Thus (2) will take the following form:

$$
k_{f}=\frac{P_{A V}}{P_{M A X}^{A V}}
$$

The algorithm for calculation the operating load factor can be presented in the following form:

1.Unloading half-hour power for the considered period;

2. Determination of average power for the entire set of TS;

3. Determination of the maximum power for each transformer substation (4);

4. Determination of the average maximum power for the set of TS (5);

5.Calculation of the adjusted value of the operating load factor (6);

6. Calculation of the adjusted value of technological consumption of electrical energy (losses) for REN.

\section{Results. Practical study}

In order to assess the applicability of the proposed approach to adjust the calculated electricity losses, and to assess the influence of operating load factor on electricity losses, a practical implementation of the algorithm was carried out.

To test the algorithm, 1 REN was selected, the calculations of electricity losses for 5 months of 2020 were adjusted, the electricity losses were calculated in accordance with [1]. The results of the adjusted calculation are presented in Table 2.

As it can be seen from the presented data, the adjustment of electricity losses was in average $6.43 \%$ or 10 thousand $\mathrm{kWh}$.

\section{Conclusions}

The performed work allowed us to draw the following conclusions:

1. Increased accuracy of calculating the electricity losses can be achieved by adjustment of operating load factor;

2. Adjustment of the operating load factor is achieved by the analysis of big data received from SEM, in particular, half-hour power for the period under consideration (month);

3. The use of the adjusted operating load factor for a set of transformer substations that are part of the

Table 2. The calculated electricity losses after adjusting the operating load factor.

\begin{tabular}{|l|c|c|c|c|c|}
\hline Month & $\begin{array}{c}\text { Operating load } \\
\text { factor before } \\
\text { adjustment, } \\
\text { p.u. }\end{array}$ & $\begin{array}{c}\text { Operating load } \\
\text { factor after } \\
\text { adjustment, } \\
\text { p.u. }\end{array}$ & $\begin{array}{c}\text { Losses } \\
\text { before } \\
\text { adjustment, } \\
\text { ths. } \mathbf{k W h}\end{array}$ & $\begin{array}{c}\text { Losses after } \\
\text { adjustment, } \\
\text { ths. } \mathbf{k W h}\end{array}$ & Deviation, \% \\
\hline January & 0.5 & 0.577278 & 208.5 & 194.5 & 7.17 \\
\hline February & 0.5 & 0.572334 & 189.1 & 177.2 & 6.75 \\
\hline March & 0.5 & 0.549563 & 158.6 & 151.5 & 4.72 \\
\hline April & 0.5 & 0.589379 & 142.6 & 131.8 & 8.21 \\
\hline May & 0.5 & 0.555825 & 124.4 & 118.1 & 5.29 \\
\hline
\end{tabular}


considered REN made it possible to refine the amount of calculated electricity losses by an average of $6.43 \%$ or 10 thousand $\mathrm{kWh}$;

Increasing the accuracy of the design value of technological consumption of electrical energy during its transportation (losses) allows one to obtain more reliable information about the structure of electricity losses. Therefore it helps to develop and apply the most effective organizational and technical measures aimed at reducing losses [16].

\section{References}

1. B.B. Kobets, I.O. Volkova, Innovative development of the electrical power industry based on the SmartGrid concept (Moscow: IAC Energy, 2010)

2. E. Tretyakov, Demand management by active consumers in intelligent electric power systems, E3S Web Conf., 164, 10004 (2020)

3. R.B. Jalilov, S.T. Latipov, G.N. Aslanova, A.A. Akhmedov, S.P. Shayimova, Key directions of development of measures to improve the reliability of electrical power systems, E3S Web Conf., 139 (2019)

4. A.G. Rusina, D.K. Khudzhasaidov, O.V. Naumov, A.N. Gorlov, Development of an intelligent system for integrated management of hydroelectric cascade modes, E3S Web Conf., 124 (2019)

5. V. Markov, A. Fedyukhin, I. Sultanguzin, B.G.Matisov, N.V. Nikitkov, V.V. Izrantsev, V.G. Knorring, G.A. Konrashkova, L.R. Mukhametova, Improvement of energy efficiency of motor fuel production at oil refinery, IOP Conf. Ser. Earth Environ. Sci., 337 (2019)

6. V. Romanova, S. Khromov, I. Suvorov, K. Balbekina, Software for optimal selection of places for installation of balancing devices in $0,4 \mathrm{kV}$ electric power systems loaded with electric motors, E3S Web Conf., 25 (2017)

7. V.E. Vorotnitsky, M.A. Kalinkina, Calculation, rationing and reduction of electrical energy losses in electrical networks (Moscow: IPC State Services, 2003)

8. E. Zamyatin, I. Voytyuk, E. Zamyatina, Increasing the energy efficiency of an enterprise by point compensating of power quality distortions, E3S Web Conf., 140 (2019)

9. Y.S. Zhelezko, A.V. Artemyev, O.V. Savchenko, Calculation, analysis and rationing of electrical power losses in electrical networks. Guide for practical calculations (Moscow: Publishing House NTs ENAS, 2005)

10. Anon 2008 Order of the Ministry of Energy of the Russian Federation of 30.12.2008 N 326 (as amended on 01.02.2010) "On the organization in the Ministry of Energy of the Russian Federation of work on the approval of standards for technological losses of electricity
11. M.I. Fursanov, A.A. Zolotoi, V. V. Makarevich et. al., Joint calculation of technical losses of electricity in electrical grids of 0.38-10 kV, Power Eng. Proc. High. Educ. institutions energy Soc. CIS, 2, 19-27 (2010)

12. R.B. Kurzhumbaeva, Analysis of methods for calculating electricity losses, Izv. NAS KR, 4, 3235 (2012)

13. A.I. Grin', Investigation of errors in calculating power and electricity losses by regression relationships, Bull. North Caucasus State Tech. Univ., 4, 69-74 (2005)

14. Y.V. Kondakov, V.S. Krylov, Analysis of methods for calculating electrical energy losses used in the wholesale electricity market, Geo-Siberia, 5, 244249 (2011)

15. I.I. Nadtoka, O.G. Skolpina, Methodology for taking into account the shape of load graphs when calculating power losses in 6-10 kV networks, Univ. news. North-Caucasian Reg. Tech. Sci. Ser., 6, 3235 (2014)

16. T.A. Musaev, O.V. Fedorov, Formation of approaches to checking the correctness of calculations of technological losses of electrical energy in 6 (10) $\mathrm{kV}$ distribution networks, Tech. opponent, 1, 30-33(2020). 